\title{
ЭКОЛОГИЧЕСКАЯ ПОЛИТИКА ЕС
}

\author{
(c) 2021 Ширёва Ирина Викторовна \\ кандидат юридических наук, доцент Департамента международного и публичного права \\ Финансовый университет при Правительстве Российской Федерации, Россия, Москва \\ E-mail: IVShiryova@fa.ru
}

В статье рассматриваются актуальные вопросы, связанные с инициативами Европейского Союза в контексте осуществления защиты естественной среды обитания.

Ключевые слова: экологическая политика, климат, Европейский союз, ООН, парниковые газы, Ф-га3ы, Европейское агентство по охране окружающей среды, Рамочная конвенция Организации Объединенных Наций об изменении климата, Парижское соглашение по климату, система торговли выбросами.

Экологическая политика и законодательство ЕС направлены на защиту естественной среды обитания, поддержание чистоты воздуха и воды, обеспечение надлежащего удаления отходов, улучшения знаний о токсичных химических веществах и оказанию помощи бизнесу в достижении устойчивой экономики [1]. ЕС и национальные правительства поставили перед собой четкие цели для руководства европейской экологической политикой 2020 года с перспективой до 2050 года поддерживая специальные программы и мероприятия в этом направлении.

В качестве приоритетов в стратегической повестке ЕС на 2019-2024 годы были определены - построение климатически нейтральной, зеленой, справедливой и социальной Европы, а также инвестирование в зеленые инициативы, которые улучшают качество воздуха и воды, способствуют устойчивому сельскому хозяйству и сохранению экологических систем и биоразнообразия; создание эффективной циркулярной экономики и хорошо функционирующего энергетического рынка ЕС, обеспечивающего устойчивую, безопасную и доступную энергию; более быстрый переход к возобновляемым источникам энергии и энергоэффективности при одновременном снижении зависимости ЕС от внешних источников энергии [2].

Необходимо отметить, что еще на европейском саммите в октябре 2014 года европейские лидеры согласились с тем, что ЕС должен активизировать свои усилия и сократить внутренние выбросы по крайней мере на $40 \%$ по сравнению с 1990 годом к 2030 году [3]. Это решение не возникло спонтанно и беспричинно, решение последовало после публикации выводов Межправительственной группы экспертов по изменению климата (МГЭИК), где говорилось, что без принятия срочных мер- изменение климата приведет к серьезным, всепроникающим и необратимым последствиям для всех людей и экосистем мира. Ограничение опасного повышения глобальной средней температуры до уровня ниже $2{ }^{\circ} \mathrm{C}$ по сравнению с доиндустриальным уровнем (цель ниже $2{ }^{\circ} \mathrm{C}$ ) потребует существенного и устойчивого сокращения выбросов парниковых газов всеми странами. Отмечалось, что этот глобальный переход к низким выбросам может быть достигнут без ущерба для роста и рабочих мест и может предоставить значительные возможности для оживления экономики не только в Европе, но и во всем мире. Действия по борьбе с изменением климата должны принести значительные выгоды с точки зрения общественного благосостояния. Однако отсрочка этого перехода приведет к увеличению общих затрат и сужению возможностей эффективного сокращения выбросов и подготовки к последствиям изменения климата. Все страны должны действовать срочно и коллективно.

С 1994 года стороны Рамочной конвенции Организации Объединенных Наций об изменении климата 1992 г. (РКИК ООН) сосредоточили свое внимание на этой проблеме, в результате чего более 90 стран, как развитых, так и развивающихся, обязались сократить свои выбросы к 2020 году [4]. В 1997 г. к РКИК ООН был принят Киотский протокол, в ст.2 п.1. было зафиксировано, что каждая Сторона, при выполнении своих определенных количественных обязательств по ограничению и сокращению выбросов, в целях поощрения устойчивого развития: осуществляет и/или далее разрабатывает в соответствии со своими национальными условиями такие 
политику и меры, как: повышение эффективности использования энергии в соответствующих секторах национальной экономики; проведение исследовательских работ, содействие внедрению, разработка и более широкое использование новых и возобновляемых видов энергии, технологий поглощения диоксида углерода и инновационных экологически безопасных технологий. В приложении А были обозначены следующие парниковые газы, выбросы которых необходимо сокращать: Диоксид углерода (CO2), Метан (CH4), Закись азота (N2O), Гидрофторуглероды (ГФУ), Перфторуглероды (ПФУ), Гексафторид серы (ГФС -SF6) [5]. Фторированные газы («Ф-газы», (ГФУ), (ПФУ), (ГФС) - это семейство искусственных газов, используемых в различных отраслях промышленности. ЕС принимает регулирующие меры по контролю за Ф-газами в рамках своей политики по борьбе с изменением климата. Ф-газы часто используются в качестве заменителей озоноразрушающих веществ, поскольку они не повреждают озоновый слой атмосферы. Однако Ф-газы являются мощными парниковыми газами, с эффектом глобального потепления до 23000 раз большим, чем углекислый газ (CO2), и их выбросы сильно растут. Известно, что выбросы Ф-газов в ЕС почти удвоились с 1990 по 2014 год - в отличие от выбросов всех других парниковых газов, которые были сокращены. Однако, благодаря законодательству EC о фторированных газах, выбросы Ф-газов снижаются с 2015 года [6].

Гидрофторуглероды (ГФУ) относительно недолговечны. Две другие группы Ф-газов, перфторуглероды (ПФУ) и гексафторид серы (SF6), могут оставаться в атмосфере в течение тысяч лет. Ф-газы используются в нескольких типах продуктов и приборов, главным образом в качестве заменителей озоноразрушающих веществ, таких как хлорфторуглероды (ХФУ), гидрохлорфторуглероды (ГХФУ) и галоны, которые постепенно выводятся из употребления в соответствии с Монреальским протоколом и законодательством ЕС. Гидрофторуглероды (ГФУ) используются в различных секторах и областях применения, таких как хладагенты в холодильном, кондиционирующем и теплонасосном оборудовании; в качестве вспенивающих агентов для пены; в качестве растворителей; а также в огнетушителях и аэрозолях.

Перфторуглероды (ПФУ) обычно используются в секторе электроники (например, для плазменной очистки кремниевых пластин), а также в косметической и фармацевтической промышленности. В прошлом ПФУ также использовались в огнетушителях, и их все еще можно найти в старых системах противопожарной защиты.

Гексафторид серы (SF6) используется в основном в качестве изолирующего газа в высоковольтных распределительных устройствах и в производстве магния и алюминия. Наличие благоприятных для климата альтернатив Ф-газам было тщательно оценено в исследованиях, проведенных для Комиссии и других органов [7].

В 2012 году стороны РКИК ООН начали переговоры о новом юридически обязательном соглашении, применимом ко всем сторонам, которое поставит мир на путь достижения цели ниже $2{ }^{\circ} \mathrm{C}$. В 2015 году это знаковое соглашение было принято в Париже. Главная цель Парижского соглашения - удержать рост глобальной средней температуры в пределах $1,5-2{ }^{\circ} \mathrm{C}$ по отношению к соответствующему показателю доиндустриальной эпохи.

За последние десятилетия Европейский союз ввел в действие широкий спектр природоохранного законодательства, были подготовлены и реализованы 7 экологических программ. Первая из них появилась в 1973 г. после проведения Стокгольмской конференции ООН по окружающей человека среде 1972 г., на которой был принят План мероприятий в отношении окружающей человека среды. В рамках этого плана Генеральная Ассамблея ООН учредила в 1972 г. Программу ООН по окружающей среде (ЮНЕП), по координации деятельности органов и учреждений системы $\mathrm{OOH}$ и созданию новых специализированных организаций, занимающихся экологическими вопросами. Последующие экологические программы действий принимались, соответственно в 1977 г. (Вторая программа), в 1983 г. (Третья программа) и в 1987 г. (Четвертая программа). Фундаментальной по содержанию явилась Пятая программа действий Сообщества в области окружающей среды, принятая в 1993 г. и получившая название «В направлении устойчивости». Пятая программа действия по окружающей среде взяла на вооружение ЕС концепцию устойчивого развития, ставшую официальной стратегией ООН по выходу человечества из экологического кризиса после проведения Конференции $\mathrm{OOH}$ по окружающей среде и развитию 1992 г. в Рио-де-Жанейро (РИО-92). Шестая про- 
грамма действий Сообщества в области окружающей среды была утверждена Решением Европейского парламента и Совета № 1600/2002/ ЕС от 22 июля 2002 г., программа экологических действий появилась непосредственно перед Всемирной встречей на высшем уровне по устойчивому развитию (РИО+10), прошедшей под эгидой ООН в Йоханнесбурге (Ю.Африка) с 26 августа по 4 сентября 2002 г. Шестая программа сфокусировала внимание на четырех приоритетных сферах действий, к ним были отнесены:

- изменение климата;

- природа и биологическое разнообразие;

- окружающая среда, здоровье и качество жизни;

- природные ресурсы и отходы.

Седьмая программа действий в области экологии была принята решением Европейского парламента и Совета № 1386/2013/ЕС от 20 ноября 2013 г. В п.1 ст.2 были обозначены следующие приоритетные цели:

- защищать, сохранять и приумножать природный капитал Союза;

- превратить Союз в ресурсо-эффективную, экологичную и конкурентоспособную низкоуглеродную экономику;

- защищать граждан Союза от давления, связанного с окружающей средой, и рисков для здоровья и благополучия;

- максимизировать преимущества законодательства Союза в области охраны окружающей среды путем улучшения его применения;

- улучшать базу знаний и фактических данных для политики Союза в области окружающей среды;

- обеспечивать инвестиции в экологическую и климатическую политику и устранить внешние экологические факторы;

- улучшать экологической интеграции и согласованности политики;

- повышать эффективность Союза в решении международных экологических и климатических проблем.

В декабре 2019 года Европейской Комиссией было подготовлено сообщение институтам ЕС Европейскому Парламенту, Европейскому Совету, Совету ЕС, Европейскому экономическому и социальному комитету и Комитету регионов, в котором была изложена Европейская зеленая (Green Deal) сделка для Европейского Союза (EC) и его граждан. В этом сообщении представлена первоначальная дорожная карта ключевых стратегий и мер, необходимых для достижения Европейской зеленой сделки, которые будут обновляться по мере развития потребностей и формулирования политических мер реагирования. Все действия и политика ЕС должны будут способствовать достижению целей Европейской «Зеленой сделки».

Необходимо отметить, что «Зеленая сделка» является неотъемлемой частью стратегии Европейской Комиссии по реализации Повестки дня Организации Объединенных Наций на период до 2030 года и целей устойчивого развития [8], а также других приоритетов, объявленных в политических руководящих принципах председателем ЕК ЕС Урсулой фон дер Ляйен [9]. В рамках «Зеленой сделки» Комиссия переориентирует процесс макроэкономической координации Европы на интеграцию целей устойчивого развития Организации Объединенных Наций, чтобы поставить устойчивость и благополучие граждан в центр экономической политики, а цели устойчивого развития-в центр разработки политики и действий ЕС [10]. В рамках Европейской зеленой сделки Комиссия представила в сентябре 2020 года план оценки воздействия, направленный на увеличение целевого показателя ЕС по сокращению чистых выбросов парниковых газов по крайней мере до 55\% к 2030 году. К июлю 2021 года Комиссия представит законодательные предложения по реализации новой цели [11].

Европейская зеленая сделка является ответом на вызовы и проблемы, связанные с изменением климата и его последствиями, направлена на защиту, сохранение и приумножение природного капитала ЕС, а также на защиту здоровья и благополучия граждан от рисков и воздействий, связанных с окружающей средой. Это новая стратегия роста, направленная на преобразование ЕС в справедливое и процветающее общество с современной, ресурсоэффективной и конкурентоспособной экономикой, в которой в 2050 году не будет выбросов парниковых газов.

ЕС уже приступил к модернизации и преобразованию экономики с целью обеспечения климатической нейтральности. Чтобы обеспечить запланированные сокращения выбросов парниковых газов, Комиссия к июню 2021 года должна рассмотреть и предложить пересмотреть, при необходимости, все соответствующие инструменты политики, связанные с климатом. Пересмотр будет касаться существующей Системы торговли выбросами [12], включая возмож- 
ное распространение европейской торговли выбросами на новые секторы, целевые показатели государств-членов по сокращению выбросов в секторах, не входящих в Систему торговли выбросами [13], и регулирование землепользования, изменений в землепользовании и лесного хозяйства. Комиссия может внести предложения в Европейский климатический пакт* [14], чтобы соответствующим образом обновить его.

Эти политические реформы помогут обеспечить эффективное ценообразование на углерод во всей экономике ЕС. Это должно помочь стимулировать изменения в поведении потребителей и бизнеса и способствовать увеличению устойчивых государственных и частных инвестиций. Различные инструменты ценообразования должны дополнять друг друга и совместно обеспечивать согласованную политическую основу. Обеспечение того, чтобы налогообложение соответствовало климатическим целям, также имеет важное значение. Комиссия может предложить пересмотреть Директиву, касающуюся налогообложения энергетических продуктов и электричества [15], уделяя особое внимание экологическим вопросам, и предлагает использовать положения Договоров, которые позволяют Европейскому парламенту и Совету принимать предложения в этой области в рамках обычной законодательной процедуры квалифицированным большинством голосов, а не единогласно.

Однако, до тех пор, пока многие международные партнеры не разделяют те же амбиции, что и ЕС, существует риск утечки углерода, либо потому, что производство переносится из ЕС в другие страны с более низкими амбициями по сокращению выбросов, либо потому, что продукция ЕС заменяется более углеродоемким импортом. Если этот риск материализуется, сокращения глобальных выбросов не произойдет, и это сорвет усилия ЕС и его отраслей по достижению глобальных климатических целей Парижского соглашения [16].

Соответственно, любое количество Гидрофторуглеродов (ГФУ), поступающее в ЕС вне системы действующих квот на ГФУ, может привести к снижению экологических выгод и недобросовестной конкуренции. Поэтому крайне важно поддерживать должное соблюдение действующих правил регулирования Ф-газов.
Регламент (ЕС) № 517/20141 («Регулирование Ф-газов») направлен на создание эффективного и пропорционального механизма сокращения выбросов фторированных парниковых газов для содействия достижению климатических целей Союза. С момента принятия Регламента № 517/20141 («Регулирование Ф-газов») в 2014 году международные переговоры продвинулись дальше в этом направлении, и в октябре 2016 года 197 стран согласились поэтапно отказаться от глобального потребление и производство ГФУ в соответствии с Монреальским протоколом («Кигали Поправка») [17]. Основной мерой для достижения сокращения выбросов фторированных парниковых газов является «ГФУ ЕС поэтапное сокращение», в соответствии с которым общее количество ГФУ, которое предприятия могут импортировать или производить в ЕС (т.е. «впервые размещаться на рынке»), постепенно сокращается до 2030 года. (измеряется в эквиваленте СО2) [18].

Статья 21(5) Регламента (ЕС) № 517/20141 («Регулирование Ф-газов») призывает Комиссию EC: «опубликовать доклад с оценкой метода распределения квот, включая влияние бесплатного распределения квот и затраты на осуществление этого Регламента в государствах-членах и возможного международного соглашения по гидрофторуглеродам. В свете этого доклада Комиссия представит, при необходимости, законодательное предложение Европейскому парламенту и Совету с целью: внесения поправок в метод распределения квот; создания соответствующего способа распределения любых возможных доходов.» В соответствии со статьей 23 Регламента предусмотрено учреждение Консультативного форума для проведения соответствующей работы. В 2017 году был опубликован доклад Комиссии ЕС [19] по оценке метода распределения квот в соответствии с Регламентом (ЕС) № 517/2014. В докладе было отмечено, что метод распределения квот затрагивает около 1100 предприятий, из которых примерно две трети являются «держателями квот» на ГФУ (оптовыми производителями и/или импортерами), в то время как остальные предприятия являются импортерами оборудования. Число новых участников значительно увеличилось и растет с каждым годом. В 2017 году, 579 предприятий были новыми участ-

\footnotetext{
* Европейский климатический пакт-это инициатива Комиссии по взаимодействию с различными заинтересованными сторонами и гражданским обществом с целью привлечения их к климатическим действиям и более устойчивому поведению.
} 
никами, что на 73\% больше, чем в 2015 году. Метод распределения для действующих компаний, основанный на историческом потреблении, обеспечивает существующим предприятиям стабильное начальное положение на рынке. Со временем доля квот, доступных этим сотрудникам, будет уменьшаться быстрее, чем общий рынок (поскольку он сокращается после поэтапного сокращения), что означает, что рыночная доля квот, выделяемых нынешним сотрудникам, будет уменьшаться с течением времени. Зарезервированные суммы для новых участников составили $11 \%$ от общего объема квот на начало поэтапного сокращения в 2015 году. Благодаря процедуре определения квот абсолютные показатели, доступные из этого резерва, будут оставаться более или менее стабильными с течением времени. С другой стороны, поскольку общий рынок сокращается после поэтапного сокращения ГФУ, относительная доля квот, выделяемых из резерва новых участников, с годами будет увеличиваться. Например, более 50\% от общей квоты будет выделено из резерва на заключительном этапе в 2030 году [20].

В докладе было отмечено, что Регламент № 517/20141 («Регулирование Ф-газов») в значительной степени опирается на обязательства, уже принятые предыдущим Регламентом (EC) № 842/200617, в частности в отношении предотвращения выбросов от оборудования, таких как проверки и ремонт утечек, сертификация и программы обучения в странах-членах, маркировка оборудования, отчетность и восстановление по истечении срока службы. При оценке предыдущего Регламента (ЕC) № 842/2006 расходы в государствах - членах, осуществляющих и применяющие эти меры, оценивались в 11,4 млн. евро в год [21]. Эта сумма включает расходы связанные с мерами по повышению осведомленности и правоприменительными мерами, такими как инспекции. В связи с централизованным управлением процессом поэтапного сокращения Европейской Комиссией, а также Европейским агентством по охране окружающей среды [22] эти расходы покрываются за счет ее существующего бюджета. Европейская комиссия, в частности осуществляет управление порталом Ф-газы и Реестром ГФУ для регистрации предприятий, квот, трансфертов квот и разрешений на квоты; пересчет новых базовых значений квот каждые три года и загрузка новых квот на ежегодной основе; контроль за ежегодной отчетностью предприятий в системе, управляемой Европейским агентством по охране окружающей среды; проверку на основе отчетности еx post соблюдения предприятиями своих лимитов квот и применение штрафных санкций в виде вычетов из будущих квот; проверку на основе отчетности ex post наличия у импортеров оборудования для ГФУ необходимых разрешений на квоты; и предоставление руководств предприятиям по использованию портала Ф-газы и Реестра ГФУ и обязательств, связанных с системой квот.

В более общем плане затраты промышленности на реализацию мер, предусмотренные в предыдущем Регламенте (ЕС) № 842/2006, ранее оценивались примерно в 1 млрд. евро в 2015 году, возросли до 1,5 млрд. евро в 2030 годах [23]. Расходы, связанные с поэтапным сокращением ГФУ, оценивались примерно в 1,5 млрд. евро в год [24]. Однако на самом деле ожидается, что затраты будут ниже. Первая цифра основана на предположении, что использование ГФУ не сократится до 2030 года, но с началом поэтапного отказа от ГФУ в соответствии с новыми правилами их использование будет резко сокращено. Вторая цифра была основана на информации только 2010 года. Таким образом, не учитывались новые технологии, появившиеся с тех пор, и тенденция к снижению стоимости экологически чистых технологий. Средние затраты на борьбу с выбросами были оценены на основе технологии, доступной в 2010 году, в размере 16 евро за тонну эквивалент СО2. Ожидается, что повышение энергоэффективности, возможно, компенсирует дополнительные первоначальные инвестиционные затраты. В 2017году был завершен только один полный «годовой»* цикл поэтапного отказа, и включение холодильного, кондиционирующего и теплонасосного оборудования в рамках поэтапного отказа началось 1 января 2017 года.

Необходимо отметить, что еще слишком рано проводить углубленную оценку функционирования механизма поэтапного отказа и тщательно оценивать все возможные последствия выбранного метода распределения квот. Тем не менее проведенный анализ и консультации с заинтересованными сторонами свидетельству-

\footnotetext{
* Один «годовой» цикл поэтапного сокращения включает распределение квот, использование квот, отчетность компании ex post и последующую проверку соответствия Комиссией. Для завершения цикла требуется примерно два года.
} 
ют о том, что поэтапный отказ функционирует должным образом. Динамика цен полностью соответствует ожиданиям, и наблюдается хорошее соблюдение общего лимита ГФУ ЕС.

Выбранный метод распределения позволяет, с одной стороны, обеспечить стабильность на рынке, а с другой-гибкость для выхода на рынок новых участников рынка. Отмечая, что предприятиям придется сократить свои продажи ГФУ в рамках поэтапного отказа, бесплатное распределение квот может принести пользу некоторым участникам рынка в большей степени, чем другие. Кроме того, наличие бесплатной квоты по простому запросу из резерва значительно увеличило количество игроков с небольшими квотами. Потребуется дальнейший мониторинг, чтобы оценить и сделать выводы, как эта ситуация для малых и новых импортеров газа будет развиваться в ближайшие годы. Кроме того, ситуация на рынке импортеров оборудования, которые в нынешней системе распределения зависят от обладателей квот для получения разрешений на их импорт, также требует постоянного мониторинга.

Нынешний метод позволяет Европейской комиссии, основываясь на онлайн-портале Ф-газы [24], внедрить систему квот с небольшим дополнительным бременем или затратами для государств-членов. Таким образом, это поможет успешно осуществить поэтапный отказ и сохранить экологические амбиции. Большинство текущих расходов в государствах-членах являются результатом обязательств, уже установленных предыдущим Регламентом (ЕС) № 842/2006. Однако, государствам-членам будет предложено увеличить взносы в существующий Многосторонний фонд, для того чтобы в будущем финансировать поправку Кигали в соответствии с их обязательствами по Монреальскому соглашению. Известно, что Комиссия в настоящее время не намерена вносить изменения в метод распределения квот. Вместо этого Комиссия сосредоточится на обеспечении плавного внедрения существующего метода и оказании помощи всем заинтересованным сторонам в лучшем понимании и соблюдении их обязательств, с тем чтобы добиться успеха в поэтапном отказе от ГФУ ЕС. В то же время Комиссия продолжит осуществлять мониторинг за функционированием метода распределения и его воздействие внимательно, отмечая при этом, что всесторонний обзор Регламента № 517/20141 («Регулирование
Ф-газов») требуется осуществить до 31 декабря 2022 года.

Известно, что одним из крупнейших торговых партнеров ЕС является КНР. В 2018 году Комиссия обратилась к внешнему подрядчику с просьбой изучить вопрос, касающийся незаконной торговли ГФУ. Данные о торговле ГФУ, имеющиеся в отчетности компаний в соответствии с правилами регулирования Ф-газов, были сопоставлены с другими соответствующими наборами данных, в частности с торговыми данными Евростата, а также данными об экспорте Китая, полученными промышленностью из китайских источников и предоставленными Комиссии. Представители промышленности предоставили Комиссии соответствующие данные, отражающие количество некоторых ГФУ, в отношении которых китайские экспортеры указали, что ожидаемым пунктом назначения экспорта будет государство-член ЕС. Были обнаружены расхождения между данными из Китая об экспорте ГФУ в ЕС (если брать по номинальной стоимости) и данными ЕС по (заявленному) ГФУ таким образом, информация по импорту из Китая может свидетельствовать о наличии незаконной торговли и возможном уклонении от уплаты таможенных пошлин [25].

Еще одна проблема, поднятая заинтересованными сторонами, заключается в том, что данные по китайскому экспорту отмечены высокие темпы роста импорта ГФУ в большинство странсоседей ЕС, в Украину; в некоторые балканские страны, особенно в Албанию. Однако в абсолютном выражении последние показатели относительно невелики по сравнению с существующей системой квот ЕС. Отмечалось, что в большинстве соседних стран ожидается некоторая положительная динамика в связи с экономическим ростом и заменой озоноразрушающих веществ ГФУ. Кроме того, учитывая вступление в силу поправки Кигали в 2019 году, некоторые импортеры, возможно, увеличили свои запасы, как это было в ЕС в 2014 году до вступления в силу действующих правил регулирования Ф-газов. Увеличение, наблюдаемое в Турции и России, составляло $\sim 10 \%$ в год, что является вероятным порядком величины для внутреннего увеличения использования. Увеличение импорта из Китая в Швейцарию более чем уравновешивается сокращением экспорта из ЕС в Швейцарию [26].

Хотя высокие темпы роста ГФУ в некоторых странах, вызывают озабоченность ЕС, важно 
подчеркнуть, что для отслеживания этих тенденций требуется более полные данные, и с целью получения таких данных ведется работа и осуществляется взаимодействие с некоторыми третьими странами.

Несмотря на существование незаконной торговли, поэтапный отказ от ГФУ по- прежнему успешно способствует инновациям и переходу к решениям, благоприятным для климата. Большая часть незаконной торговли, вероятно, осуществляется в форме уклонения от уплаты таможенных пошлин. Хотя становится очевидным, что такое уклонение от уплаты таможенных пошлин имеет место, на данном этапе представляется невозможным количественно оценить эту деятельность на основе имеющихся данных [27].

Что касается оценок, основанных на данных об экспорте Китая, то возникают вопросы относительно того, являются ли эти китайские данные надежными или согласуются с данными ЕС. Имеющиеся данные показывают, что несколько стран -соседей ЕС имеют неожиданно высокие темпы роста импорта ГФУ. Даже если данные на данном этапе не позволяют оценить масштабы незаконной деятельности, очевидно, что таможенный контроль должен быть усилен, поскольку любое количество ГФУ, поступающее в ЕС подлежит мониторингу, поскольку существующая система квот потенциально может повлечь снижение экологических выгод и эта ситуация приведет к недобросовестной конкуренции.

В 2020 году ЕК было подготовлен План восстановления для Европы, который направлен на стимулирование зеленых и цифровых переходов, на то, чтобы сделать европейскую экономику более справедливой и более устойчивой для будущих поколений [28].

Подводя итог, напрашивается очевидный вывод, о том, что Европейский союз поставил крайне амбициозную цель и проводит достаточно серьезную полномасштабную работу на пути реализации обозначенной цели, вовлекая в этот процесс не только государства-члены, но и иные государства, с которыми ЕС имеет торговоэкономические отношения.

\section{Библиографический список}

1. Сайт ЕС [Электронный ресурс] - Режим доступа: // Environment and climate change - EUR-Lex (europa.eu) (дата обращения 10.04.2021)

2. Сайт ЕС [Электронный ресурс] - Режим доступа: // European Union priorities for 2019-2024 | European Union (europa.eu) (дата обращения 09.04.2021)

3. Сайт EC [Электронный ресурс] - Режим доступа: // EUR-Lex - 52015DC0081 - EN - EUR-Lex (europa.eu) (дата обращения 10.04.2021)

4. Сайт ЕС [Электронный ресурс] - Режим доступа: // EUR-Lex - 52015DC0081 - EN - EUR-Lex (europa.eu) (дата обращения 10.04.2021)

5. Сайт ООН [Электронный ресурс] - Режим доступа: // https://www.un.org/ru/documents/decl_conv/ conventions/kyoto.shtml (дата обращения 11.04.2021)

6. Сайт ЕС [Электронный ресурс] - Режим доступа:// https://ec.europa.eu/clima/policies/f-gas_en (дата обращения 10.04.2021)

7. Сайт ЕС [Электронный ресурс] - Режим доступа: // https://ec.europa.eu/clima/policies/f-gas/legislation_ en\#tab-0-2 (дата обращения 09.04.2021)

8. Сайт ООН [Электронный ресурс] - Режим доступа: // https://sustainabledevelopment.un.org/post2015/ transformingourworld (дата обращения 11.04.2021)

9. Political Guidelines of President elect Ursula von der Leyen: Political guidelines for the next Commission (20192024) - «A Union that strives for more: My agenda for Europe»: Сайт ООН [Электронный ресурс] - Режим доступа: // European Commission (europa.eu) (дата обращения 12.04.2021)

10. Сайт ЕС [Электронный ресурс] - Режим доступа: // EUR-Lex - 52019DC0640 - EN - EUR-Lex (europa.eu) (дата обращения 09.04.2021)

11. Сайт ЕС [Электронный ресурс] - Режим доступа: // https://ec.europa.eu/clima/policies/ets_en\#tab-0-0 (дата обращения 09.04.2021)

12. Документ ЕС [Электронный ресурс] - Режим доступа: // Consolidated version of Directive 2003/87/EC of the European Parliament and of the Council establishing a scheme for greenhouse gas emission allowance trading within the Community and amending Council Directive 96/61/ЕС. (дата обращения 11.04.2021) 
13. Документ EC Regulation (EU) 2018/842 on binding annual greenhouse gas emission reductions by Member States from 2021 to 2030 contributing to climate action to meet commitments under the Paris Agreement and amending Regulation (EU) No 525/2013. Система торговли выбросами EC: работает во всех странах ЕС, а также в Исландии, Лихтенштейне и Норвегии (государства ЕС-ЕАСТ), ограничивает выбросы от примерно 10000 установок в энергетическом секторе и обрабатывающей промышленности, а также авиакомпаний, работающих между этими странами, охватывает около 40\% выбросов парниковых газов в ЕС.- [Электронный ресурс] Режим доступа: // https://ec.europa.eu/info/law_en (дата обращения 11.04.2021)

14. Документ EC - [Электронный ресурс] - Режим доступа: // https://europa.eu/climate-pact/system/ files/2020-12/20201209\%20European\%20Climate\%20Pact\%20Communication.pdf (дата обращения 10.04.2021)

15. Документ EC Council Directive 2003/96/EC restructuring the Community framework for the taxation of energy products and electricity.- [Электронный ресурс] - Режим доступа: // https://ec.europa.eu/info/law_en (дата обращения 11.04.2021)

16. Документ ООН [Электронный ресурс] - Режим доступа: // https://unfccc.int/files/essential_background/ convention/application/pdf/english_paris_agreement.pdf (дата обращения 10.04.2021)

17. Документ ООН [Электронный ресурс] - Режим доступа: // http://ozone.unep.org/sites/ozone/files/pdfs/FAQs Kigali_Amendment_v3.pdf (Дата обращения 11.04.2021)

18. Сайт ЕС [Электронный ресурс] - Режим доступа: // https:/ec.europa.eu/clima/sites/default/files/f-gas/ legislation/docs/com_2017_377_en.pdf (Дата обращения 11.04.2021)

19. Сайт ЕС [Электронный ресурс] - Режим доступа: // com_2017_377_en.pdf (еuropa.eu) (Дата обращения 11.04.2021)

20. Сайт ЕС [Электронный ресурс] - Режим доступа: // com_2017_377_en.pdf (europa.eu) (Дата обращения 11.04.2021)

21. Сайт ЕС [Электронный ресурс] - Режим доступа://https://ec.europa.eu/clima/sites/clima/files/f-gas/docs/2011_ study_en.pdf (Дата обращения 11.04.2021)

22. Сайт ЕС [Электронный ресурс] - Режим доступа: // https://www.eea.europa.eu/about-us (Дата обращения 11.04.2021)

23. Сайт ЕС [Электронный ресурс] - Режим доступа: // com_2017_377_en.pdf (europa.eu) (Дата обращения 11.04.2021)

24. European Commission COM(2012) 643 final Impact Assessment (2012). [Электронный ресурс] - Режим доступа: // https://ec.europa.eu/clima/sites/clima/files/f-gas/legislation/docs/swd_2012_364_en.pd (Дата обращения 12.04.2021)

25. Сайт ЕС [Электронный ресурс] - Режим доступа: // https://webgate.ec.europa.eu/ods2/resources/ home?domainKey=fgas (Дата обращения 11.04.2021)

26. Сайт ЕС [Электронный ресурс] - Режим доступа: // https:/ec.europa.eu/clima/sites/default/files/f-gas/ legislation/docs/report_illegal_trade_hcf_en.pdf (Дата обращения 12.04.2021)

27. Сайт ЕС [Электронный ресурс] - Режим доступа: // https://ec.europa.eu/clima/sites/default/files/f-gas/ legislation/docs/report_illegal_trade_hcf_en.pdf (Дата обращения 12.04.2021)

28. Сайт ЕС [Электронный ресурс] - Режим доступа: // https://ec.europa.eu/info/strategy/recovery-plan-europe_ en (Дата обращения 13.04.2021) 